\title{
ADAPTAÇÃO E AVALIAÇÃO DO MODELO INFOCROP PARA SIMULAÇÃO DO RENDIMENTO DE GRÃOS DA CULTURA DO ARROZ IRRIGADO
}

\author{
LIDIANE C. WALTER ${ }^{1}$, HAMILTON T. ROSA ${ }^{2}$, NEREU A. STRECK ${ }^{3}$, \\ SIMONE E. T. FERRAZ ${ }^{4}$
}

\begin{abstract}
RESUMO: Este trabalho teve como objetivo adaptar e avaliar o modelo InfoCrop para simulação do rendimento de grãos da cultura do arroz irrigado, em Santa Maria - RS. O rendimento de grãos da cultura do arroz irrigado foi simulado, considerando-se três versões do modelo InfoCrop com adaptações para cultivares locais. Os rendimentos simulados foram comparados com os rendimentos observados no município de Santa Maria, no período 1996/1997 a 2008/2009, disponibilizados pelo Instituto Riograndense do Arroz (IRGA), e com rendimentos de experimentos realizados na Universidade Federal de Santa Maria (UFSM), entre os anos agrícolas de 1998/1999 e 2005/2006. O modelo InfoCrop capturou a variação interanual do rendimento de grãos de arroz irrigado para o município de Santa Maria e dos experimentos realizados na UFSM. A raiz do erro quadrático médio da simulação de rendimento de grãos com a Versão 3 do modelo InfoCrop (melhor desempenho), considerando todo o conjunto de dados observados, foi de $0,850 \mathrm{Mg} \mathrm{ha}^{-1}$, com tendência de superestimativa, que pode ter ocorrido pelo fato de o modelo considerar uma situação de rendimento potencial, o que nem sempre acontece em lavouras comerciais.
\end{abstract}

PALAVRAS-CHAVE: modelagem matemática, grãos, produtividade, Oryza sativa.

\section{ADAPTION AND EVALUATION OF THE INFOCROP MODEL FOR SIMULATING GRAIN YIELD OF IRRIGATED RICE}

\begin{abstract}
This study aimed to adapt and evaluate the InfoCrop model for simulating grain yield of irrigated rice in Santa Maria, state of Rio Grande do Sul, Brazil. The grain yield of irrigated rice was simulated considering three versions of the InfoCrop model with adaptations for local rice cultivars. Simulated yields were compared to the yields observed in the Santa Maria county surveyed by the Instituto Riograndense do Arroz (Institute of Rice of Rio Grande do Sul - IRGA) from 1996/97 to 2008/09, and to the yields of experiments conducted at the Universidade Federal de Santa Maria (Federal University of Santa Maria - UFSM) from 1998/1999 to 2005/2006. The InfoCrop model captured the interannual variability of the grain yield of irrigated rice for the Santa Maria county and the experiments conducted at UFSM. The root mean squared error of the simulation of grain yield using the Version 3 of the InfoCrop model (better performance), considering all data observed, was $0.850 \mathrm{Mg} \mathrm{ha}^{-1}$, with overestimation trend, which may have occurred because the model considers a situation of potential yield, which does not always occur in commercial farming.
\end{abstract}

KEYWORDS: mathematical modeling, grains, yield, Oryza sativa.

\footnotetext{
${ }^{1}$ Programa de Pós-graduação em Engenharia Agrícola, Centro de Ciências Rurais (CCR), Universidade Federal de Santa Maria (UFSM), Santa Maria - RS.

${ }^{2}$ Programa de Pós-graduação em Agronomia, CCR, UFSM. Santa Maria - RS.

${ }^{3}$ Departamento de Fitotecnia, CCR, UFSM, Av. Roraima, 1000, Santa Maria - RS, nstreck1@ smail.ufsm.br.

${ }^{4}$ Departamento de Física, Centro de Ciências Naturais e Exatas, UFSM.

Recebido pelo Conselho Editorial em: 22-12-2010

Aprovado pelo Conselho Editorial em: 3-2-2012
} 


\section{INTRODUÇÃO}

O Brasil é o maior produtor de arroz fora da Ásia, sendo cultivados anualmente cerca de 2,8 milhões de hectares com arroz (USDA, 2010), dos quais 1,3 milhão de hectares são de várzeas, onde é cultivado arroz irrigado por inundação. O Rio Grande do Sul (RS) é o Estado responsável por $60 \%$ da produção brasileira de arroz, com cerca de 7 milhões de $\mathrm{Mg}$ produzidas por ano em uma área de mais de 1 milhão de hectares, com rendimento de grãos médio no Estado de 6,45 $\mathrm{Mg} \mathrm{ha}^{-1}$ no ano agrícola 2009/2010 (IRGA, 2010). A Depressão Central do RS, onde está situado o município de Santa Maria, é uma das principais regiões produtoras de arroz irrigado no Estado.

$\mathrm{Na}$ área agrícola, modelos matemáticos são ferramentas de baixo custo para se realizar estudos de resposta das culturas agrícolas a práticas de manejo e à mudança climática. Modelos matemáticos são uma simplificação da realidade que, devidamente adaptados e testados em diferentes ambientes, permitem descrever as interações entre a planta ou cultura e o ambiente. No Brasil, exemplos de uso de modelos agrícolas em estudos numéricos para simular o rendimento das culturas agrícolas e outros processos do crescimento e desenvolvimento vegetal são frequentes na literatura (SIQUEIRA et al., 2000; CARDOSO et al., 2004; STRECK \& ALBERTO, 2006; LAGO, 2008; GROHS et al., 2009; MERCANTE et al., 2010).

Existem vários modelos de simulação do rendimento de grãos de arroz, alguns mais complexos como o CERES-Rice (TIMSINA \& HUMPHREYS, 2006) e o ORYZA (BOUMAN et al., 2004), ambos calibrados para as condições Asiáticas, e outros com algumas simplificações, principalmente na maneira de calcular a produção de matéria seca na planta, que facilitam sua utilização, como o InfoCrop (AGGARWAL et al., 2006a), desenvolvido e avaliado na Índia, e o WARM (CONFALONIERI et al., 2009), avaliado para as condições da Europa. Destes, o modelo InfoCrop é um modelo mecanístico, genérico e que permite simular os efeitos do clima, do solo, de manejo da cultura, de danos das principais pragas e doenças, além de possibilitar a simulação do impacto ambiental de agroecossistemas. Comparando os modelos InfoCrop e ORYZA1 na Índia, KRISHNAN et al. (2007) encontraram que o modelo InfoCrop apresentou melhor desempenho, com menor erro na simulação. Esse modelo é de simples aplicação e requer dados de entrada facilmente disponíveis, características atrativas para os usuários desta ferramenta. No entanto, nenhum dos modelos de simulação do rendimento de arroz acima citados foi adaptado ou testado para as condições de cultivo e clima brasileiros, o que constituiu a motivação para realizar este trabalho.

O objetivo deste trabalho foi adaptar e avaliar o modelo InfoCrop para a simulação do rendimento potencial de grãos da cultura do arroz irrigado em Santa Maria - RS.

\section{MATERIAL E MÉTODOS}

O modelo InfoCrop (AGGARWAL et al., 2006a) foi primeiramente desenvolvido e avaliado para as condições asiáticas, na Índia. A partir do modelo original, neste trabalho, realizaram-se modificações que resultaram em três versões, que são a seguir descritas.

Na Versão 1 do modelo InfoCrop, a maioria dos coeficientes originais foi mantida (AGGARWAL et al., 2006 a, b; BOUMAN et al., 2004), com exceção de alguns coeficientes que não estavam disponíveis nas publicações que descrevem o modelo, e algumas adaptações foram feitas para as cultivares locais, conforme descrição a seguir:

No modelo InfoCrop é usado o conceito de soma térmica para a simulação do desenvolvimento da cultura, em que a duração de cada fase é controlada pelo tempo térmico necessário para completar cada fase. A duração das fases do ciclo de desenvolvimento das cultivares utilizadas, em graus dia $\left({ }^{\circ} \mathrm{C}\right.$ dia), foi calculada por LAGO (2008), em uma série de experimentos conduzidos durante quatro anos agrícolas, em Santa Maria - RS. No modelo original, o ciclo da cultura é dividido em três fases: fase de emergência (semeadura-emergência), fase vegetativa (emergência-antese) e fase reprodutiva (antese-maturidade fisiológica). No entanto, 
LAGO (2008) propõe uma divisão do ciclo de desenvolvimento da cultura que considera o estádio de diferenciação do primórdio floral, o qual é importante no manejo da cultura, já que é neste momento que se recomenda a aplicação da segunda parcela da adubação nitrogenada, em função de o componente do rendimento número de grãos por panícula ser definido neste momento do ciclo (SOSBAI, 2007). Assim, o modelo foi adaptado para considerar quatro fases do ciclo de desenvolvimento da cultura (Figura 1). O estádio de desenvolvimento da cultura foi calculado diariamente, de modo que a fase de emergência compreendesse os estádios de -1 (semeadura) até 0 (emergência), a fase vegetativa inicia-se no estádio 0 e termina no estádio 0,65 (diferenciação do primórdio floral), a fase reprodutiva inicia-se no estádio 0,65 e termina no estádio 1 (antese) e a fase de enchimento de grãos corresponde ao período entre os estádios 1 e 2 (maturidade fisiológica), como pode ser visualizado na Figura 1.

O cálculo da soma térmica diária foi realizado com a temperatura mínima e máxima diária do ar e as três temperaturas cardinais do desenvolvimento da cultura: temperatura base, temperatura ótima e temperatura máxima, segundo metodologia utilizada por LAGO (2008). As temperaturas cardinais foram consideradas as mesmas para as cultivares, mas variam de acordo com a fase de desenvolvimento (Tabela 1). A soma térmica foi acumulada diariamente (Soma Térmica acumulada, STa). Quando a STa calculada atingia o valor predeterminado da duração de cada fase, em cada cultivar usada nas simulações (Tabela 1) segundo LAGO (2008), considerou-se que a fase estava completa.

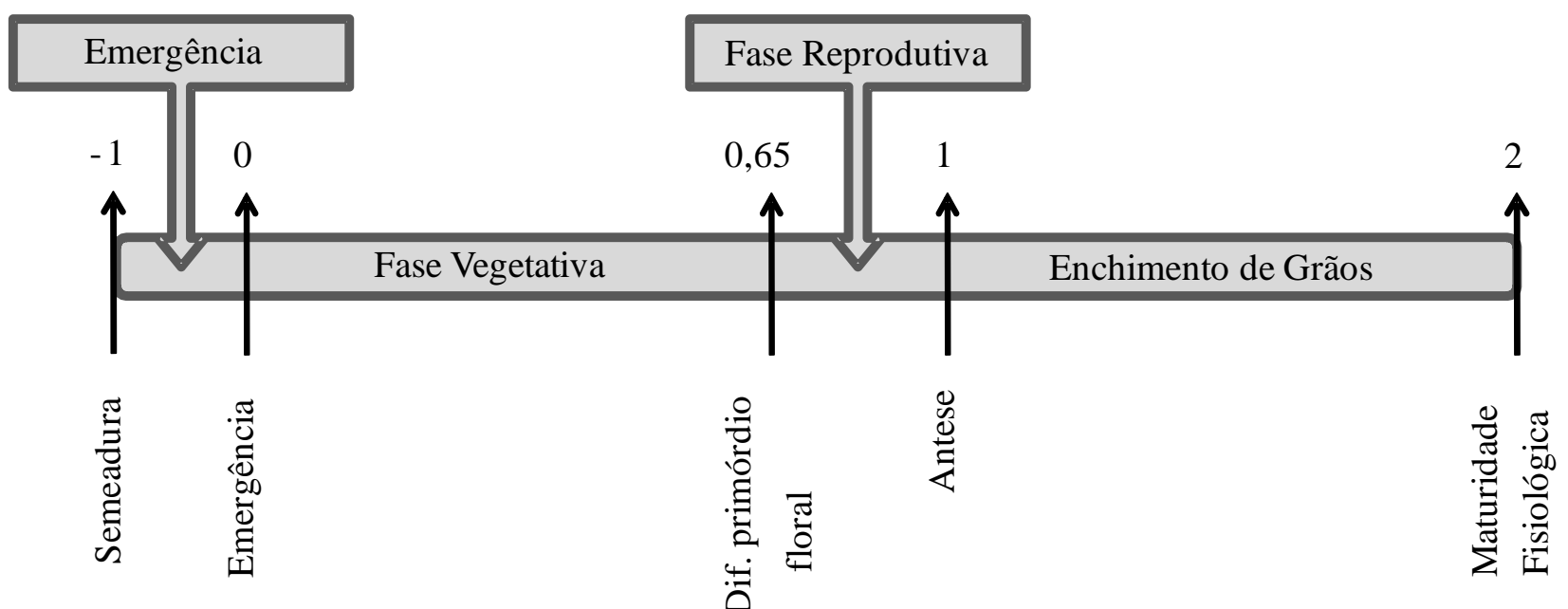

FIGURA 1. Ciclo de desenvolvimento do arroz irrigado usado no modelo InfoCrop. Developmental cycle of irrigated rice used in the InfoCrop model.

A fase vegetativa (emergência - antese) é considerada como o período em que a cultura do arroz irrigado tem sensibilidade ao fotoperíodo. No modelo InfoCrop, dependendo do fotoperíodo e da sensibilidade da cultivar utilizada ao fotoperíodo, calcula-se um fator de correção para a soma térmica desta fase (AGGARWAL et al., 2006a). Nessa simulação, não foi considerado o efeito do fotoperíodo sobre o desenvolvimento, pois as cultivares locais não têm sensibilidade ao fotoperíodo e porque LAGO (2008) não considerou efeito do fotoperíodo sobre a fenologia destas cultivares no cálculo da soma térmica.

A produção de matéria seca pela cultura é calculada como uma função da Eficiência do Uso da Radiação (EUR) e do Índice de Área Foliar (IAF), relacionando a radiação solar interceptada com o crescimento das plantas. O valor de EUR usado foi de $2,39 \mathrm{~g} \mathrm{MJ}^{-1}$, citado por KINIRY et al. (2001), para cultivares modernas de arroz, similares às usadas neste estudo em termos de hábito de crescimento (semianãs) e rendimento de grãos. Para o cálculo da produção diária de matéria seca na planta, utilizou-se a radiação fotossinteticamente ativa (RFA) como sendo $50 \%$ da densidade de fluxo de radiação solar global, em MJ m${ }^{-2} \mathrm{dia}^{-1}$, que foi calculada a partir do brilho solar pela equação de Angstron, modificada por Prescott e Penman (ESTEFANEL et al., 1990). O modelo 
considera que o coeficiente de extinção das folhas à radiação solar é de 0,4 até a antese e 0,6 após a antese (BOUMAN et al., 2004).

TABELA 1. Temperaturas cardinais e soma térmica das fases do ciclo de desenvolvimento de cultivares de arroz irrigado. Cardinal temperatures and thermal time of the developmental phases of the irrigated rice cultivars. (Fonte: LAGO, 2008)

\begin{tabular}{lcccc}
\hline \multirow{2}{*}{ Coeficiente } & \multicolumn{3}{c}{ Fase do Ciclo de Desenvolvimento } \\
\cline { 2 - 5 } & Emergência & Vegetativa & Reprodutiva & $\begin{array}{c}\text { Enchimento de } \\
\text { Grãos }\end{array}$ \\
\hline Temperatura base & $11^{\circ} \mathrm{C}$ & $11^{\circ} \mathrm{C}$ & $15^{\circ} \mathrm{C}$ & $15^{\circ} \mathrm{C}$ \\
Temperatura ótima & $30^{\circ} \mathrm{C}$ & $30^{\circ} \mathrm{C}$ & $25^{\circ} \mathrm{C}$ & $23^{\circ} \mathrm{C}$ \\
Temperatura máxima & $40^{\circ} \mathrm{C}$ & $40^{\circ} \mathrm{C}$ & $35^{\circ} \mathrm{C}$ & $35^{\circ} \mathrm{C}$ \\
Soma térmica (IRGA 421) & $50^{\circ} \mathrm{C}$ dia & $437,9^{\circ} \mathrm{C}$ dia & $108,2^{\circ} \mathrm{C}$ dia & $113,1^{\circ} \mathrm{C}$ dia \\
Soma térmica (IRGA 417) & $50^{\circ} \mathrm{C}$ dia & $560,0^{\circ} \mathrm{C}$ dia & $146,3^{\circ} \mathrm{C}$ dia & $109,7^{\circ} \mathrm{C}$ dia \\
Soma térmica (EPAGRI 109) & $50^{\circ} \mathrm{C}$ dia & $735,4^{\circ} \mathrm{C}$ dia & $241,8^{\circ} \mathrm{C}$ dia & $98,9^{\circ} \mathrm{C}$ dia \\
\hline
\end{tabular}

Uma vez simulada a produção de matéria seca total diária, calcula-se a partição da matéria seca total entre raízes e parte aérea. A fração destinada à parte aérea é então distribuída entre os diferentes órgãos da planta (folhas, colmos e panículas), de acordo com o estádio de desenvolvimento da cultura. A partir da antese, inicia-se o processo de senescência das folhas e do colmo, calculado pela perda de uma fração do peso acumulado em cada órgão da planta até o momento. A matéria seca alocada para as folhas, em $\mathrm{g} \mathrm{m}^{-2} \mathrm{dia}^{-1}$, multiplicada pela área foliar específica, em $\mathrm{m}^{2} \mathrm{~g}^{-1}$ (calculada em função do estádio de desenvolvimento), permite que o peso das folhas seja transformado em área, a partir da qual se calcula o índice de área foliar (IAF), que é atualizado diariamente no cálculo da produção de matéria seca. No primeiro dia de simulação da produção de matéria seca, a área foliar inicial de uma planta é considerada $0,0001 \mathrm{~m}^{2}$ (BOUMAN et al., 2004) com densidade de 200 plantas $\mathrm{m}^{-2}$ (SOSBAI, 2007), resultando em um IAF inicial de 0,02. Considerou-se que uma parte dos colmos também tem atividade fotossintética, sendo a contribuição dos colmos acrescentada ao valor do IAF.

O número de espiguetas formadas em um dia no modelo é calculado por um fator de formação de espiguetas (65 espiguetas por g de matéria seca) em função da matéria seca total produzida naquele dia $\left(\mathrm{g} \mathrm{m}^{-2} \mathrm{dia}^{-1}\right)$, resultando em espiguetas $\mathrm{m}^{-2} \mathrm{dia}^{-1}$, acumulado desde a diferenciação do primórdio floral até a antese. $\mathrm{O}$ número final de espiguetas formado sofre uma correção em função da esterilidade das espiguetas causada por temperaturas extremas no período crítico (pré-florescimento e florescimento), que fica entre os estádios 0,75 e 1,2 para as temperaturas muito baixas e entre os estádios de 0,96 e 1,22 para as temperaturas muito elevadas. A esterilidade de espiguetas causada pelas temperaturas muito baixas ( $\mathrm{Sc}$ ) e a esterilidade de espiguetas por temperaturas muito elevadas (Sh) são calculadas por (BOUMAN et al., 2004):

$$
S c=\frac{1-\left(4,6+0,054 \times\left(\sum(22-T d)\right)^{1,56}\right.}{100}
$$

em que, Td - temperatura média diária (somatório de [22 - Td] no período crítico).

$$
S h=\frac{1}{1+e^{(0,853 \times(T d m-36,6))}}
$$

em que, Tdm é a temperatura máxima diária (média do período crítico).

A partir da antese, parte da matéria seca produzida começa a ser translocada para a panícula, dando início ao enchimento das espiguetas, formando os grãos. Após a antese, em adição à matéria seca produzida diariamente, $10 \%$ das reservas previamente acumuladas no colmo são translocadas 
para os grãos todos os dias. A simulação é finalizada quando a fase de enchimento de grãos se completa (maturidade fisiológica) ou quando o peso potencial é alcançado ( $0,0249 \mathrm{~g}$ por grão).

$\mathrm{Na}$ Versão 2 do modelo InfoCrop, incluiu-se o efeito da temperatura na EUR, utilizando uma função de resposta com quatro temperaturas cardinais descrita por SOLTANI et al. (2001), conforme representado na Figura 2. Com esta função, a EUR é máxima quando a temperatura média diária do ar está na faixa ótima (entre 22 e $32^{\circ} \mathrm{C}$ ) e é multiplicada por um fator de correção em temperaturas sub e supraótimas, que reduz linearmente a EUR até zero, quando a temperatura é igual ou menor que $9{ }^{\circ} \mathrm{C}$ ou igual ou maior que $45^{\circ} \mathrm{C}$ (Figura 2 ).

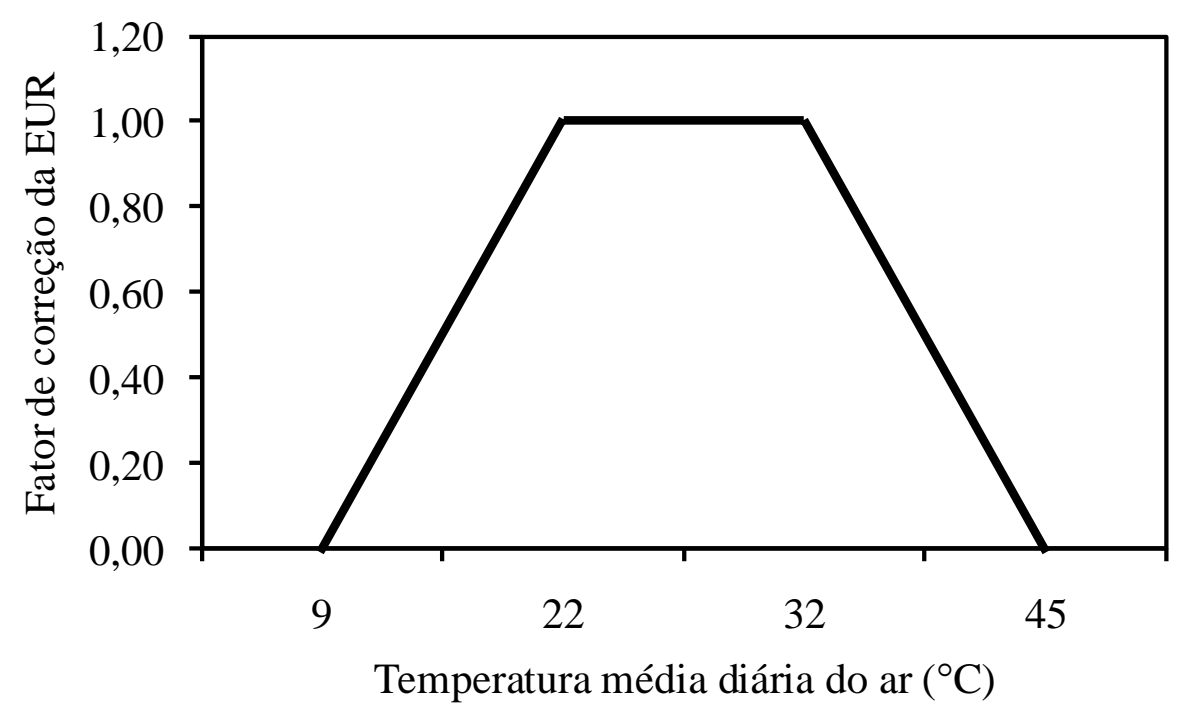

FIGURA 2. Função de resposta da Eficiência do Uso da Radiação (EUR) à temperatura média diária do ar. The response function of Radiation Use Efficiency (RUE) to daily mean air temperature.

Nas simulações com as Versões 1 e 2 do modelo InfoCrop, observou-se que algumas vezes o valor do IAF máximo simulado pelo modelo era bastante elevado e não representava a realidade. Em uma busca bibliográfica, foi encontrado o valor de 7,5 como IAF máximo, em condições de alta adubação nitrogenada, com a cultivar IRGA 417, em Santa Maria (CAMARGO et al., 2008 a). Este valor de 7,5 foi estabelecido como o IAF máximo, o que constituiu a Versão 3 do modelo InfoCrop, mantendo-se as alterações das versões 1 e 2 .

As três versões do modelo InfoCrop foram implementadas em linguagem Fortran, utilizando o compilador Force - Versão 2.0.8p. Não foram considerados os efeitos de pragas, doenças e plantas invasoras, e os manejos de irrigação e adubação não foram considerados limitantes, portanto o rendimento de grãos simulado representa o potencial produtivo.

Para avaliação das três versões do modelo InfoCrop, o rendimento de grãos de arroz foi simulado utilizando dados meteorológicos (temperaturas mínima e máxima diária do ar e brilho solar) da Estação Meteorológica Convencional, pertencente ao $8^{\circ}$ DISME/INMET e localizada no Departamento de Fitotecnia da Universidade Federal de Santa Maria (UFSM), em Santa Maria-RS (latitude: $29^{\circ} 43^{\prime} \mathrm{S}$, longitude: $53^{\circ} 43^{\prime} \mathrm{W}$ e altitude: $95 \mathrm{~m}$ ). Santa Maria está situada na região fisiográfica da Depressão Central, uma das principais regiões orizícolas do Estado (IRGA, 2010), onde predomina o cultivo de arroz irrigado por inundação.

As três versões foram avaliadas comparando-se os valores simulados com os dados de safra catalogados pelo Instituto Riograndense do Arroz (IRGA, 2010), no período entre os anos agrícolas de 1996/1997 a 2008/2009. Nesta avaliação, rodaram-se as três versões do modelo, em três datas de semeadura $(20 / 09,20 / 10$ e 20/11) que são representativas do período de semeadura recomendado para a região (SOSBAI, 2007). Foram utilizadas três cultivares de arroz irrigado do tipo moderno 
(semianãs), diferentes em relação à duração do ciclo de desenvolvimento, recomendadas para o cultivo no RS (SOSBAI, 2007): IRGA 421 - cultivar muito precoce, utilizada no manejo de áreas infestadas com arroz-vermelho (principal planta invasora da cultura), em função de seu ciclo de desenvolvimento bastante curto; IRGA 417 - ciclo precoce, cultivar mais utilizada nas áreas de arroz irrigado no Estado do Rio Grande do Sul, por sua alta produtividade, ótima qualidade dos grãos, alto vigor inicial das plântulas e boa adaptabilidade a todas as regiões orizícolas do RS; EPAGRI 109 - cultivar de ciclo longo e alto rendimento de grãos. Os dados de rendimento disponibilizados pelo IRGA, são relativos à média do município de Santa Maria, sem distinção de cultivares ou datas de semeadura. Para uma comparação mais justa entre rendimento simulado e observado pelo IRGA foi utilizado o rendimento médio das simulações (cultivares e datas de semeadura) em cada ano agrícola, já que os valores observados também são uma média de diferentes cultivares (com ciclos distintos), em diversas datas de semeadura.

Uma segunda avaliação das três versões do modelo InfoCrop foi realizada comparando-se o rendimento simulado com resultados de experimentos realizados na área de várzea da UFSM, entre os anos agrícolas 1998/1999 e 2005/2006, com as cultivares e datas de semeaduras utilizadas em cada um destes experimentos (Tabela 2). Esta segunda avaliação foi realizada, pois o rendimento de grãos é simulado com dados meteorológicos de uma Estação Meteorológica instalada a aproximadamente $500 \mathrm{~m}$ do local destes experimentos. Além disso, em experimentos, há um controle maior dos fatores bióticos que afetam o rendimento, como pragas, doenças e plantas invasoras, e as demais práticas de manejo são realizadas com mais rigor e próximas das recomendações para a cultura. Estes cuidados resultam em rendimentos mais próximos do potencial produtivo da cultura, situação que é simulada pelas três versões do modelo usadas neste estudo.

TABELA 2. Dados de experimentos com arroz irrigado realizados na UFSM e utilizados na avaliação do modelo InfoCrop. Data from experiments with rice conducted at UFSM and used in the evaluation of the InfoCrop model.

\begin{tabular}{ccccl}
\hline $\begin{array}{c}\text { Ano } \\
\text { Agrícola }\end{array}$ & $\begin{array}{c}\text { Data de } \\
\text { Semeadura }\end{array}$ & Cultivar & $\begin{array}{c}\text { Rendimento } \\
\left(\mathrm{kg} \mathrm{ha}^{-1}\right)\end{array}$ & \multicolumn{1}{c}{ Referência } \\
\hline $1998 / 1999$ & $01 / 11 / 1998$ & BRS TAIM & $7.595,0$ & Weber et al. (2003) \\
$1998 / 1999$ & $01 / 11 / 1998$ & IRGA 417 & $8.447,0$ & Weber et al. (2003) \\
$2002 / 2003$ & $30 / 11 / 2002$ & BRS TAIM & $4.818,0$ & Marchesan et al. (2007) \\
$2003 / 2004$ & $18 / 10 / 2003$ & BRS TAIM & $10.154,0$ & Marchesan et al. (2007) \\
$2004 / 2005$ & $23 / 10 / 2004$ & IRGA 420 & $6.971,0$ & Marchesan et al. (2007) \\
$2004 / 2005$ & $28 / 10 / 2004$ & IRGA 422 CL & $8.411,0$ & Santos et al. (2007) \\
$2004 / 2005$ & $29 / 10 / 2004$ & IRGA 422 CL & $8.346,0$ & Villa et al. (2006) \\
$2005 / 2006$ & $03 / 11 / 2005$ & IRGA 417 & $9.783,0$ & Camargo et al. (2008 a) \\
$2005 / 2006$ & $03 / 11 / 2005$ & IRGA 417 & $10.025,0$ & Camargo et al. (2008 b) \\
\hline
\end{tabular}

As estatísticas usadas para avaliar o desempenho das três versões do modelo foram a raiz do erro quadrático médio (REQM), o Viés Médio (BIAS), o teste de t-pareado, ao nível de 5\% entre dados simulados e observados, e a regressão linear simples entre dados simulados versus observados. A REQM foi calculada por: $\mathrm{REQM}=\left[\Sigma(\mathrm{Pi}-\mathrm{Oi})^{2} / \mathrm{N}\right]^{0,5}$, e o Viés Médio foi calculado por: VIÉS $=\Sigma(\mathrm{Pi}-\mathrm{Oi}) / \mathrm{N}$, em que: Pi é o valor simulado; Oi é o valor observado, e N é o número de observações. Na regressão linear, quando o modelo é satisfatório, o coeficiente angular não difere de 1 , e o coeficiente linear não difere de zero.

\section{RESULTADOS E DISCUSSÃO}

Na avaliação do modelo InfoCrop com os dados catalogados pelo IRGA, o REQM na Versão 1 foi de $1,014 \mathrm{Mg} \mathrm{ha}^{-1}$, diminuindo para $0,836 \mathrm{Mg} \mathrm{ha}^{-1}$ na Versão 2 e para $0,795 \mathrm{Mg} \mathrm{ha}^{-1}$ na Versão 3 do modelo InfoCrop. Na avaliação do modelo com dados de experimentos realizados na UFSM, o 
REQM foi de 0,955 $\mathrm{Mg} \mathrm{ha}^{-1}$ na Versão 1, diminuindo para 0,801 $\mathrm{Mg} \mathrm{ha}^{-1}$ e $0,791 \mathrm{Mg} \mathrm{ha}^{-1}$ na Versão 3. A redução do REQM com as modificações incluídas nas Versões 2 e 3 do modelo InfoCrop indica que tais alterações foram adequadas, melhorando a simulação do rendimento de grãos da cultura do arroz irrigado. Em uma avaliação do modelo InfoCrop para as condições Asiáticas, KRISHNAN et al. (2007) encontraram um valor de REQM de 0,795 $\mathrm{Mg} \mathrm{ha}^{-1}$, portanto próximo dos resultados da Versão 3. Assim, a seguir, são apresentados os resultados das simulações com a Versão 3 do modelo InfoCrop, pois esta é a versão mais adequada para a simulação do rendimento de grãos da cultura do arroz irrigado para Santa Maria - RS.

A simulação do rendimento de grãos com a Versão 3 do modelo InfoCrop para as safras de 1996/1997 até 2008/2009 e os rendimentos observados nestes anos para Santa Maria estão na Figura 3. Pode-se observar que a simulação com o modelo InfoCrop conseguiu capturar a variação interanual do rendimento de grãos de arroz observado no município de Santa Maria, no período (Figura 3), e houve tendência de superestimativa do rendimento médio de grãos com viés médio igual a $0,633 \mathrm{Mg} \mathrm{ha}^{-1}$. Os resultados do modelo em simular o rendimento de grãos em cada experimento realizado na UFSM estão representados na Figura 4, onde se observa novamente tendência de superestimativa em quatro experimentos, mas em cinco experimentos o valor simulado é muito próximo do valor observado (Viés Médio de $0,981 \mathrm{Mg} \mathrm{ha}^{-1}$ ).

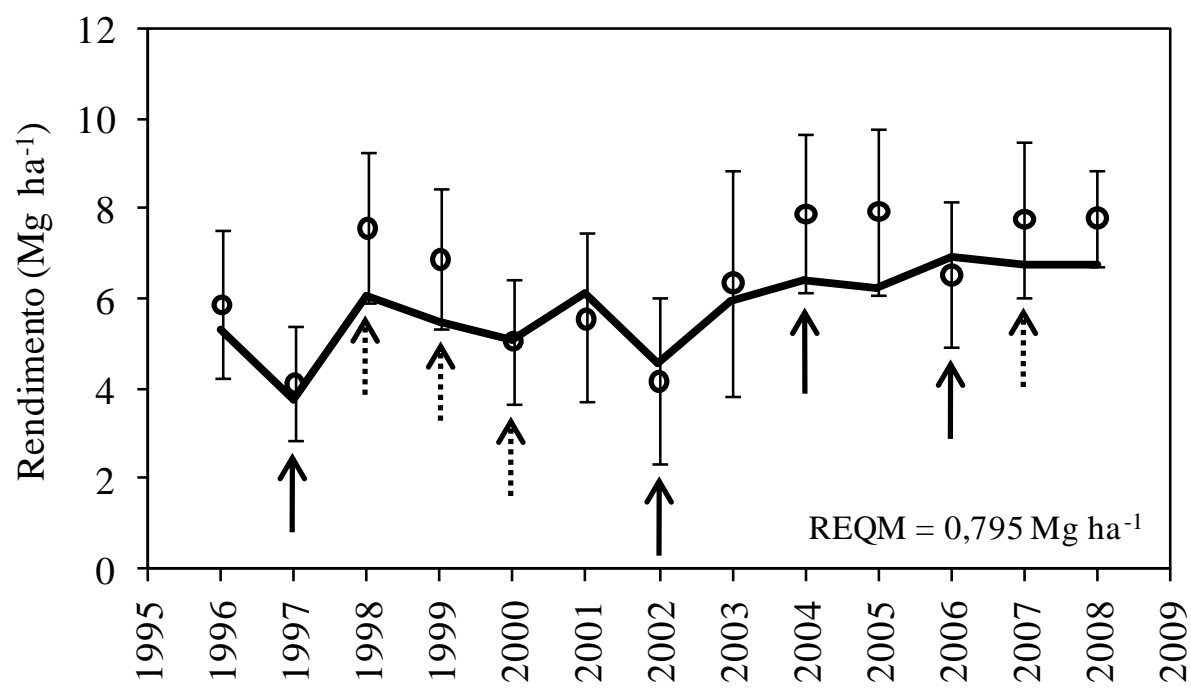

Anos

- Simulado Observado

$\longrightarrow$ Anos de El Niño $\quad$........ Anos de La Niña

FIGURA 3. Rendimento de grãos da cultura do arroz irrigado simulado com a versão 3 do modelo InfoCrop e observado no município de Santa Maria-RS (IRGA, 2010). A barra representa o Erro-Padrão da média. REQM é raiz do erro quadrático médio. Kernel yield of irrigated rice simulated with the Version 3 of the InfoCrop model and observed in the county of Santa Maria, RS (IRGA, 2010). Bars represent the mean standard error. REQM is the root mean squared error.

Nas Figuras 3 e 4 estão indicados por setas os anos em que ocorreram eventos de El Niño e La Niña (PAULA et al., 2010). Na região Sul do Brasil, os anos de El Niño são caracterizados por precipitação e umidade relativa do ar acima da normal, enquanto nos anos de La Niña a precipitação e a umidade relativa do ar geralmente são abaixo da normal e são marcadas por grandes secas na região (FONTANA \& BERLATO, 1997; GRIMM et al., 1998; STRECK et al., 2008). Estas anomalias levam a menores rendimentos de arroz irrigado em anos de El Niño e maiores rendimentos em anos de La Niña, no RS, comparados aos anos Neutros, em função principalmente 
da disponibilidade de radiação solar maior em anos de La Niña, que permite maior crescimento e melhor utilização da adubação nitrogenada. Nos anos de El Niño, os valores simulados ficam bem próximos do observado (Figura 3), com exceção do ano de 2004 (safra de 2004/2005), que foi um ano em que o evento de El Niño foi de intensidade fraca (PAULA et al., 2010) e que se descaracterizou a partir de dezembro de 2004, quando teve início um período de estiagem e alta disponibilidade de radiação solar no Rio Grande do Sul que se prolongou até o mês de março de 2005, o que é benéfico para a cultura do arroz no RS, por ser irrigada. Já nos anos de La Niña, os valores simulados afastam-se mais dos valores observados, com exceção do ano 2000 (safra de 2000/2001) quando o evento foi classificado como La Niña de intensidade fraca (PAULA et al., 2010).

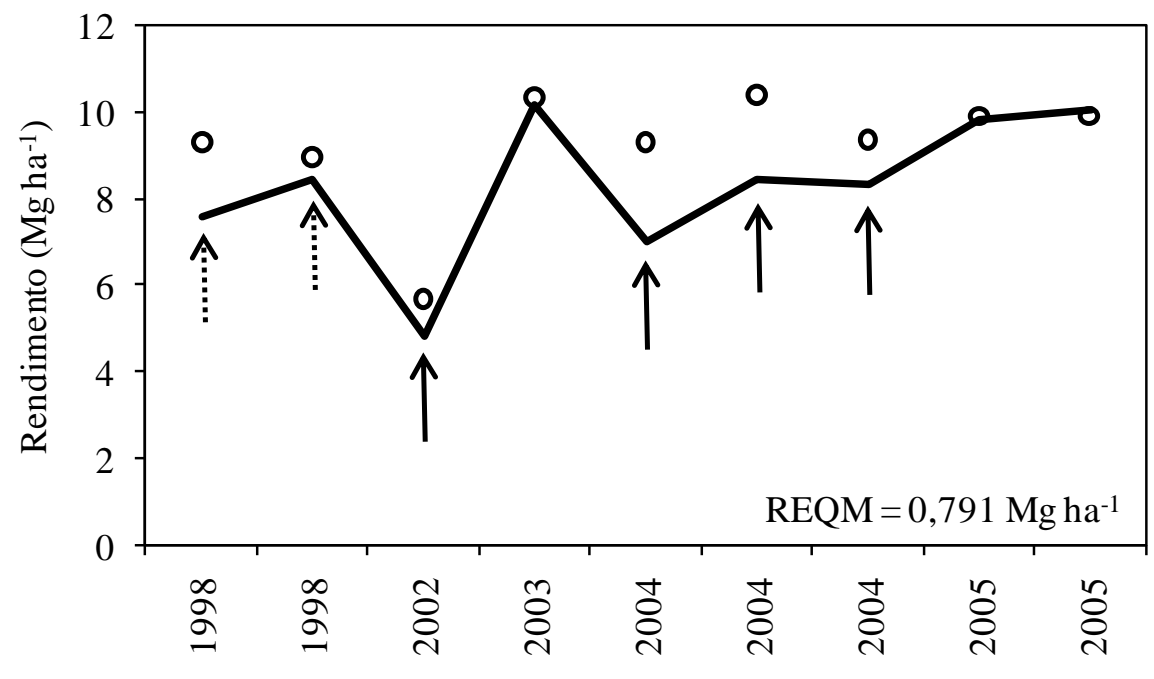

Experimentos

- Simulado Observado

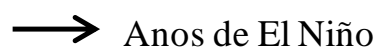

Anos de La Niña

FIGURA 4. Rendimento de grãos da cultura do arroz irrigado simulado com a versão 3 do modelo InfoCrop e observado em experimentos realizados na UFSM. REQM é raiz do erro quadrático médio. Kernel yield of irrigated rice simulated with the Version 3 of the InfoCrop model and observed in experiments conducted at UFSM. REQM is the root mean squared error.

Pelos resultados das Figuras 3 e 4 e pelo teste do Viés Médio, o modelo InfoCrop superestimou o rendimento de grãos da cultura do arroz irrigado em anos em que houve alta disponibilidade de radiação solar e poucos dias chuvosos. Uma possível explicação para isto é a simplificação assumida no modelo no que diz respeito à fotossíntese, através de um valor único de EUR no cálculo da produção de matéria seca ao longo da estação de crescimento. Esta metodologia tem sido utilizada em modelos de simulação com resultados satisfatórios (AGGARWAL et al., $2006 \mathrm{a}, \mathrm{b})$ e com a vantagem de requerer dados de entrada mais simples para o cálculo. No entanto, com esta simplificação não são considerados alguns fatores importantes, como a abertura estomática, que tem grande influência na fotossíntese das plantas (TAIZ \& ZEIGER, 2008). Outra hipótese para explicar a superestimativa do modelo em anos com elevada disponibilidade de radiação solar é a possibilidade de, no manejo do nitrogênio, haver limitação deste nutriente para a produção potencial nas lavouras comerciais do Estado, e como a versão do modelo InfoCrop utilizada nesta simulação assume não haver limitação de nitrogênio, pode haver uma superestimativa do rendimento de grãos pelo modelo.

Na Figura 5, está o Gráfico 1:1 do rendimento simulado e observado, considerando-se todo o conjunto de dados observados (IRGA e UFSM). Observa uma maior frequência de dados acima da 
linha 1:1, com um Viés Médio igual a $0,775 \mathrm{Mg} \mathrm{ha}^{-1}$, o que indica superestimativa do modelo InfoCrop, e um REQM de $0,85 \mathrm{Mg} \mathrm{ha}^{-1}$. Os rendimentos de grãos da cultura do arroz irrigado simulados e observados (Figura 5) não diferiram pelo teste de t-pareado, ao nível de 5\% de probabilidade, indicando que o modelo simula satisfatoriamente a tendência dos rendimentos da cultura. A análise de regressão linear indicou que o coeficiente angular da reta entre valores simulados e observados não é diferente de 1, o que confirma a capacidade preditiva da tendência dos rendimentos, com uma superestimativa de $0,709 \mathrm{Mg} \mathrm{ha}^{-1}$, representado pelo coeficiente linear da regressão (Figura 5).

Os valores de RQME da Versão 3 do modelo correspondem a aproximadamente $13,7 \%$ da média do rendimento observado em todo o período pelo IRGA $\left(5,819 \mathrm{Mg} \mathrm{ha}^{-1}\right)$ e $9,5 \%$ da média do rendimento obtida nos experimentos $\left(8,283 \mathrm{Mg} \mathrm{ha}^{-1}\right)$. $\mathrm{O}$ modelo InfoCrop avaliado na Índia apresentou um erro correspondente a 8,3\% do rendimento observado (AGGARWAL et al., 2006 b). Os erros encontrados com esta versão do modelo InfoCrop são, portanto, próximos do valor correspondente encontrado na avaliação do modelo original, feita por AGGARWAL et al. (2006 b). O maior erro para Santa Maria pode ser em função da diferença entre os locais em que o modelo foi avaliado e as diferenças entre as cultivares utilizadas nestas avaliações. Alguns ajustes foram realizados no modelo para melhorar as simulações, mas muitos coeficientes originais foram mantidos no modelo, pois não se dispõe destas informações para cultivares brasileiras, o que é motivo para se realizarem experimentos futuros visando a determinar estes coeficientes. Apesar disso, o desempenho do modelo pode ser considerado satisfatório de acordo com as estatísticas: teste de t-pareado (não houve diferença entre observado e simulado) e análise de regressão (coeficiente angular não diferiu de 1).

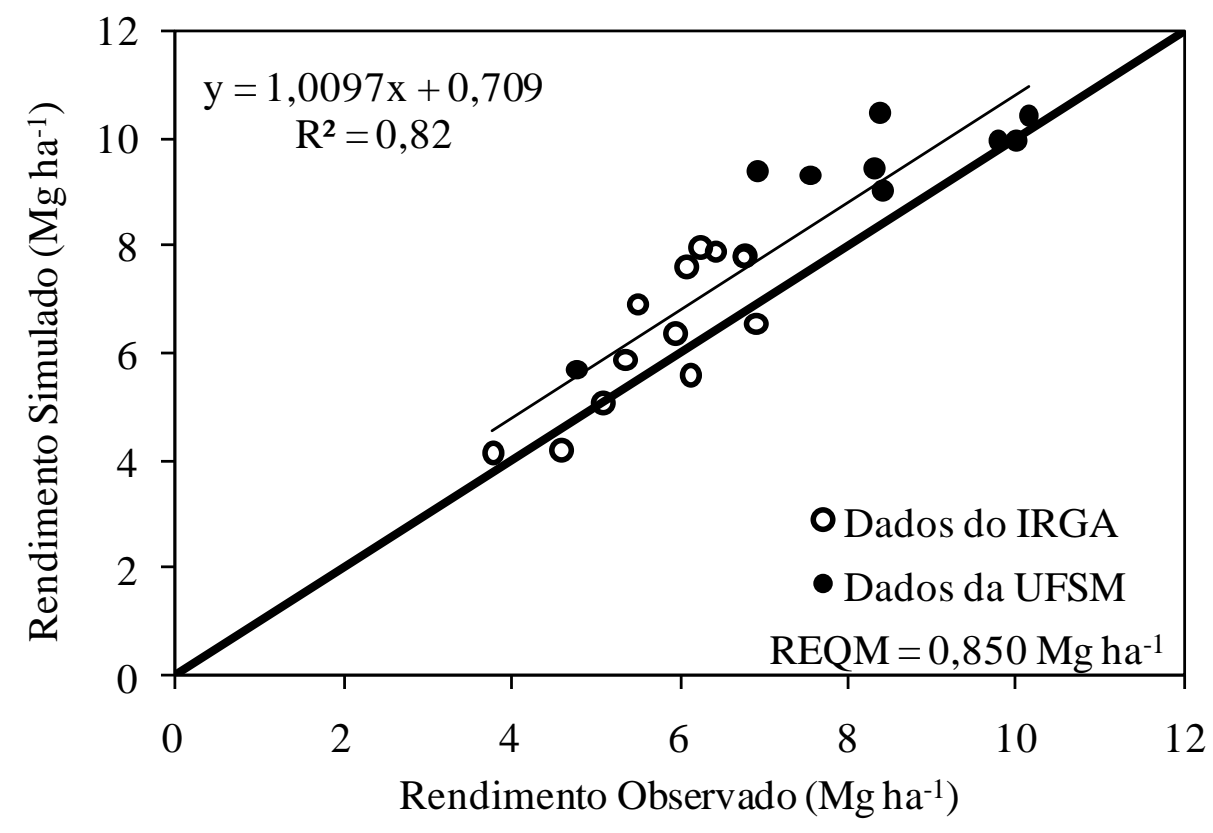

FIGURA 5. Rendimento de grãos de arroz irrigado simulado pela versão 3 do modelo InfoCrop versus rendimento de grãos observado no município de Santa Maria (IRGA, 2010) e em experimentos realizados na UFSM. Kernel yield of irrigated rice simulated with the Version 3 of the InfoCrop model versus observed kernel yield in the county of Santa Maria (IRGA, 2010) and in experiments conducted at UFSM.

As três versões do modelo InfoCrop usadas neste estudo simulam o rendimento potencial da cultura do arroz irrigado, sem considerar efeitos de pragas, doenças e plantas invasoras, fatores que são difíceis de eliminar no campo, e na maioria das vezes, inclusive, são tolerados até certo nível de dano, para que o controle seja viável economicamente. Nestas versões do modelo InfoCrop, também não são considerados efeitos abióticos devido a eventos meteorológicos, como ventos 
fortes, que afetam a esterilidade de espiguetas (SOSBAI, 2007) e provocam acamamento das plantas, a umidade relativa e o déficit de saturação do ar que afetam a fotossíntese da planta (TAIZ \& ZEIGER, 2008) e fatores relacionados ao manejo da água e da adubação, principalmente da adubação nitrogenada, que tem bastante influência no rendimento de grãos da cultura do arroz irrigado (FREITAS et al., 2001), entre outros fatores que têm efeito direto ou indireto no rendimento de grãos de arroz. Todos esses fatores acabam potencialmente afastando o rendimento observado do simulado com o modelo InfoCrop, resultando em superestimativa (Figura 5). No entanto, o desempenho do modelo foi satisfatório, indicando que a versão 3 do modelo InfoCrop pode ser usada na estimativa do rendimento potencial de grãos da cultura do arroz irrigado de cultivares usadas no Rio Grande do Sul e, posteriormente, possam ser considerados fatores bióticos e abióticos que interferem no rendimento final de grãos.

\section{CONCLUSÕES}

A Versão 3 do modelo InfoCrop tem desempenho satisfatório para a simulação do rendimento de grãos da cultura do arroz irrigado em Santa Maria - RS.

\section{REFERÊNCIAS}

AGGARWAL, P.K.; KALRA, N.; CHANDER, S.; PATHAK, H. InfoCrop: A dynamic simulation model for the assessment of crop yields, losses due to pests, and environmental impact of agroecosystems in tropical environments. I. Model description. Agricultural Systems, Netherlands, v.89, p.1-25, 2006 a.

AGGARWAL, P.K.; BANERJEE, B.; DARYAEI, M.G.; BHATIA, A.; BALA, A.; RANI, S.; CHANDER, S.; PATHAK, H.; KALRA, N. InfoCrop: A dynamic simulation model for the assessment of crop yields, losses due to pests, and environmental impact of agro-ecosystems in tropical environments. II. Performance of the model. Agricultural Systems, Netherlands, v.89, p.4767, 2006 b.

BOUMAN, B.A.M.; KROPFF, M.J.; TUONG, T.P.; WOPEREIS, M.C.S.; TEN BERGE, H.F.M.; Van LAAR, H.H. ORYZA2000: Modeling Lowland Rice. Version 2.12, November, 2004. Disponível em: <www.knowledgebank.irri.org/oryza2000/default.htm.>. Acesso em: 20 maio 2008.

CAMARGO, E.R.; MARCHESAN, E.; ROSSATO, T.L.; TELÓ, G.M.; AROSEMENA, D.R. Influência da aplicação de nitrogênio e fungicida no estádio de emborrachamento sobre o desempenho agronômico do arroz irrigado. Bragantia, Campinas, v.67, n.1, p.153-159, 2008a.

CAMARGO, E.R.; MARCHESAN, E.; AVILA, L.A.; SILVA, L.S.; ROSSATO, T.L.; MASSONI, P.F. Manutenção da área foliar e produtividade de arroz irrigado com a aplicação de fertilizantes foliares no estádio de emborrachamento. Ciência Rural, Santa Maria, v.38, n.5, p.1.439-1.442, 2008 b.

CARDOSO, C.O.; FARIA, R.T.; FOLEGATTI, M.V. Simulação do rendimento e riscos climáticos para o milho safrinha em londrina - PR, utilizando o modelo CERES-Maize. Engenharia Agrícola, Jaboticabal, v.24, n.2, p.291-300, 2004.

CONFALONIERI, R.; ACUTIS, M.; BELLOCCHI, G.; DONATELLI, M. Multi-metric evaluation of the models WARM, CropSyst, and WOFOST for rice. Ecological Modelling, Amsterdam, v.220, p.1.395-1.410, 2009.

ESTEFANEL, V.; SCHNEIDER, F.M.; BERLATO, M.A.; BURIOL, G.A.; HELDWEIN, A.B. Insolação e radiação solar na região de Santa Maria - RS: I - Estimativa da radiação solar global incidente a partir dos saldos de insolação. Revista do Centro de Ciências Rurais, Santa Maria, v.20, p.203-218, 1990. 
FONTANA, D.C.; BERLATO, M.A. Influência do El Niño Oscilação Sul sobre a precipitação pluvial no Estado do Rio Grande do Sul. Revista Brasileira de Agrometeorologia, Santa Maria, v.5, n.1, p.127-132, 1997.

FREITAS, J.G.; AZZINI, L.E.; CANTARELLA, H.; BASTOS, C.R.; CASTRO, L.H.S.M.; GALLO, P.B.; FELÍCIO, J.C. Resposta de cultivares de arroz irrigado ao nitrogênio. Scientia Agrícola, Piracicaba, v.58, n.3, p.573-579, 2001.

GRIMM, A.M.; FERRAZ, S.E.T.; GOMES, J. Precipitation anomalies in Southern Brazil associated with El Niño and La Niña events. Journal of Climate, Boston, v.11, p.2.863-2.880, 1998.

GROHS, D.S.; BREDEMEIER, C.; MUNDSTOCK, C.M.; POLETTO, N. Modelo para estimativa do potencial produtivo em trigo e cevada por meio do sensor Greenseeker. Engenharia Agrícola, Jaboticabal, v.29, n.1, p.101-112, 2009.

IRGA. INSTITUTO RIO GRANDENSE DO ARROZ. Dados de safra. Porto Alegre, 2010. Disponível em:

<520ara://www.irga.rs.gov.br/index.php?action=dados_safra_detalhes\&cod_dica=276> Acesso em: 30 set. 2010.

KINIRY, J.R.; McCAULEY, G.; XIE, Y.; ARNOLD, J.G. Rice parameters describing crop performance of four U.S. cultivars. Agronomy Journal, Madison, v.93, p.1.354-1.361, 2001.

KRISHNAN, P.; SWAIN, D.K.; BHASKAR, B.C.; NAYAK, S.K.; DASH, R.N. Impact of elevated $\mathrm{CO}_{2}$ and temperature on rice yield and methods of adaptation as evaluated by crop simulation studies. Agriculture, Ecosystems and Environment, Amsterdam, v.122, p.233-242, 2007.

LAGO, I. Desenvolvimento do arroz e do arroz-vermelho: modelagem e resposta à mudança climática. 2008. 94 f. Dissertação (Mestrado em Agronomia) - Universidade Federal de Santa Maria, Santa Maria, 2008.

MARCHESAN, E.; GARCIA, G.A.; CAMARGO, E.R.; MASSONI, P.F.S.; AROSEMENA, D.R.; OLIVEIRA, A.P.B.B. Manejo da irrigação em cultivares de arroz no sistema pré-germinado. Ciência Rural, Santa Maria, v.37, n.1, p.45-50, 2007.

MERCANTE, E.; LAMPARELLI, R.A.C.; URIBE-OPAZO, M.A.; ROCHA, J.V. Modelos de regressão lineares para estimativa de produtividade da soja no oeste do Paraná, utilizando dados espectrais. Engenharia Agrícola, Jaboticabal, v.30, n.3, p.504-517, 2010.

PAULA, G.M.; STRECK, N.A.; ZANON, A.J.; ELTZ, F.L.F.; HELDWEIN, A.B.; FERRAZ, S.E.T. Influência do fenômeno El Niño na erosividade das chuvas na região de Santa Maria (RS). Revista Brasileira de Ciência do Solo, Viçosa-MG, v.34, p.1.315-1.323, 2010.

SANTOS, F.M.; MARCHESAN, E.; MACHADO, S.L.O.; VILLA, S.C.C.; AVILA, L.A.; MASSONI, P.F.S. Controle químico de arroz-vermelho na cultura do arroz irrigado. Planta Daninha, Londrina, v.25, n.2, p.405-412, 2007.

SIQUEIRA, O.J.W.; STEINMETZ, S.; FERREIRA, M.F.; COSTA, A.C.; WOZNIAK, M.A. Mudanças climáticas projetadas através dos modelos GISS e reflexos na produção agrícola brasileira. Revista Brasileira de Agrometeorologia, Santa Maria, v.8, n.2, p.311-320, 2000.

SOLTANI, A.; ZEINALI, E.; GALESHI, S.; NIARI, N. Simulating GFDL predicted climate change impacts on rice cropping in Iran. Journal of Agricultural Science and Technology, Tehrãn, v.3, p.81-90, 2001.

SOSBAI. SOCIEDADE SUL BRASILEIRA DE ARROZ IRRIGADO. Arroz irrigado: recomendações técnicas da pesquisa para o sul do Brasil. Pelotas: SOSBAI, 2007. 161 p.

STRECK, N.A.; ALBERTO, C.M. Estudo numérico do impacto da mudança climática sobre o rendimento de trigo, soja e milho. Pesquisa Agropecuária Brasileira, Brasília, v.41, n.9, p.1.3511.359, 2006. 
STRECK, N.A.; ROSA, H.T.; WALTER, L.C.; BOSCO, L.C.; LAGO, I.; HELDWEIN, A.B. O fenômeno El Niño oscilação sul e a variabilidade interanual da evaporação do tanque Classe A e da umidade relativa do ar em Santa Maria - RS. Ciência Rural, Santa Maria, v.38, n.5, p.1.452-1.455, 2008.

TAIZ, L.; ZEIGER, E. Fisiologia vegetal. 4.ed. Porto Alegre: Artemed, 2008. 820 p.

TIMSINA, J.; HUMPHREYS, E. Performance of CERES-Rice and CERES-Wheat models in ricewheat systems: A review. Agricultural Systems, Netherlands, v.90, p.5-31, 2006.

USDA. UNITED STATES DEPARTMENT OF AGRICULTURE. Foreign agricultural service. production, supply and distribution Online: Custom Query, 2010. Disponível em:

<http://www.fas.usda.gov/psdonline/psdQuery.aspx> Acesso em: 30 set. 2010.

VILLA, S.C.C.; MARCHEZAN, E.; MASSONI, P.F.S.; SANTOS, F.M.; AVILA, L.A.;

MACHADO, S.L.O.; TELO, G.M. Controle de arroz-vermelho em dois genótipos de arroz (Oryza sativa) tolerantes a herbicidas do grupo das imidazolinonas. Planta Daninha, Londrina, v.24, n.3, p.549-555, 2006.

WEBER, L.; MARCHEZAN, E.; CARLESSO, R.; MARZARI, V. Cultivares de arroz irrigado e nutrientes na água de drenagem em diferentes sistemas de cultivos. Ciência Rural, Santa Maria, v.33, n.1, p.27-33, 2003. 